\title{
Impacted Ring in the Penis: A Crisis Rescued by Plier
}

\author{
Sanjeev Chauhan ${ }^{1}$ Kirti Rana ${ }^{1}$ Manjeet Kumar ${ }^{2}$ Pamposh Raina ${ }^{2}$
}

1 Department of Radiology, Indira Gandhi Medical College and Hospital, Shimla, Himachal Pradesh, India

2 Department of Urology, Indira Gandhi Medical College and Hospital, Shimla, Himachal Pradesh, India

\author{
Address for correspondence Manjeet Kumar, MBBS, MS, MCh, \\ Department of Urology, Indira Gandhi Medical College and Hospital, \\ Shimla, Himachal Pradesh 171001, India \\ (e-mail: manjeetkumar.1014@gmail.com).
}

J Health Allied Sci ${ }^{\mathrm{NU}}$ 2022;12:212-213.

\begin{abstract}
Keywords

- penile ring

- impacted

- pliers

- metallic rings

A trapped penile ring is a urological emergency rarely seen. An impacted ring in penis is a real emergency uncommonly faced by a urologist. Emergent removal of the penile ring is indicated to prevent gangrene and damage to the penis. The insertion of these rings for autoerotic purposes is not uncommon. However, this can lead to impacted, stuck articles, rings in the penis. These patients present with symptoms ranging from mild penile pain, swelling to gangrenous changes in the penis. The removal of ring constricting penis is a penile-saving procedure. We describe a patient with a stuck ring in the penis and the technique of removal of the impacted penile ring by a household device plier. In case of emergency, the pliers are a useful tool for removing a strangulating penile ring
\end{abstract}

\section{Introduction}

A penile ring stuck in the penis is a medical emergency uncommonly seen in an emergency department. These rings are inserted, by especially psychiatric patients, for selfstimulation and masturbation. Prompt management is crucial to prevent penile gangrene. We present a rare case report with a penile ring stuck in the penis that was timely managed.

\section{Case Summary}

A 39-year-old married male presented to emergency services with complaints of penile swelling, penile pain, and impacted ring for 1 day. He had no significant past psychiatric history. He was under the influence of alcohol, when for sexual gratification he had inserted a ring from a chain to his penis. He got an erection but started having pain and engorged penis. He tried to remove the ring but failed to do so. He waited for the resolution of penile engorgement for 6 hours, but did not get relief from swelling. He came to the hospital emergency department with a tense and turgid penis. A gentle attempt was made to remove the ring; however, all efforts were in vain. An intravenous line was set up, and the patient was given analgesics, sedatives, and antibiotics. The ring was made of steel, with a thickness of $3 \mathrm{~mm}$, and the internal diameter of the ring was $2.5 \mathrm{~cm}$. Ring ends were overlapping and were tightly fitting at the coronal sulcus leading to pain and swelling of the glans (-Fig. 1).

With the help of two metallic household pliers, ends of metallic rings were separated and the ring was removed. The swelling subsided after the removal of the ring. Psychiatry consultation was taken. The patient was placed on antibiotics and analgesics and was discharged home after 36 hours with no adverse effects. He followed for 12 months with no shortand long-term complications.

\section{Discussion}

Articles made of plastic, metal, and rubber bands are used by some people to achieve erection and orgasm by constricting
DOI https://doi.org/ 10.1055/s-0041-1736279. ISSN 2582-4287.

\footnotetext{
(c) 2021. Nitte (Deemed to be University). All rights reserved. This is an open access article published by Thieme under the terms of the Creative Commons Attribution-NonDerivative-NonCommercial-License, permitting copying and reproduction so long as the original work is given appropriate credit. Contents may not be used for commercial purposes, or adapted, remixed, transformed or built upon. (https://creativecommons.org/ licenses/by-nc-nd/4.0/) Thieme Medical and Scientific Publishers Pvt. Ltd., A-12, 2nd Floor, Sector 2, Noida-201301 UP, India
} 


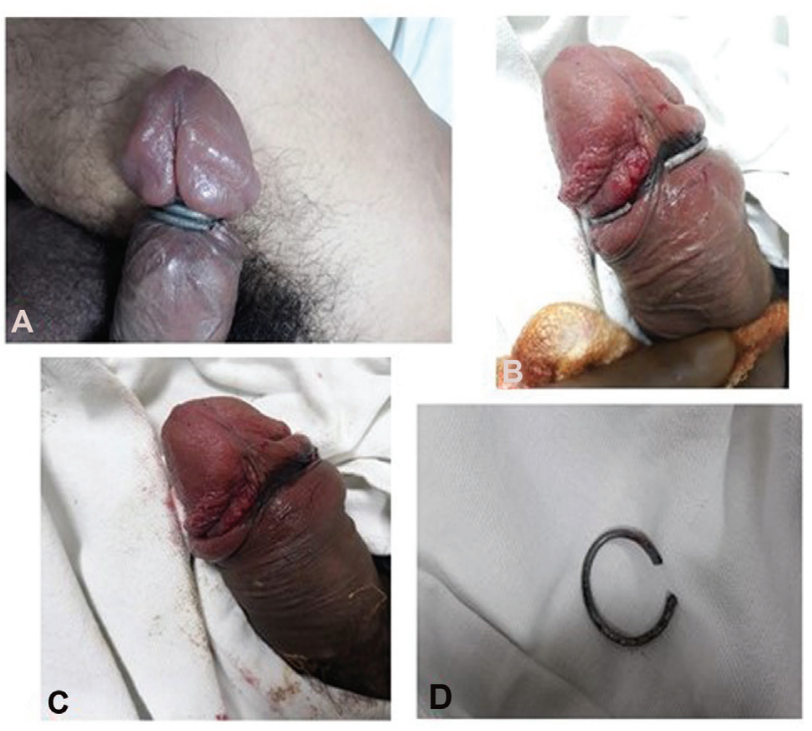

Fig. 1 (A) Impacted penile ring, (B) penile ring loosened, and (C-D). removed penile ring.

penis. Strangulation of the penis can be caused by materials such as thread, hair, a rubber band, wedding ring, engine bearing, hammerhead, bull ring, plastic bottle, or metal plumbing cuff, with each requiring a different type of cutting device. Intentional use of articles or devices including metallic rings to enhance sexual performance and orgasm is not uncommon. These articles cause constriction of the penis leading to decreased venous flow and helping to achieve a penile erection and maintain it. Patients having erectile dysfunction use these devices to attain and sustain the penile erection. Young males as well as psychiatric patients use these to achieve sexual pleasure. Sometimes these devices could not be removed after insertion. If left untreated, it may lead to ischemia, necrosis, and sometimes autoamputation of the penis. Complications reported are urinary retention, distal hypoesthesia, ulceration, desquamating epithelium, urethral stricture, urethral fistulas, priapism, gangrene, and amputation. These patients usually present late due to shame and regret, especially in India. ${ }^{1,2}$

Cutting is the most common method described for the removal of these rings. Nonmetallic and thin objects are easy to remove. Metal objects are difficult to remove. Appropriate cutting tools may be difficult to obtain, especially in emergencies. The process of removal of these rings is timeconsuming with the possibility of iatrogenic penile injury. Several techniques have been described to remove these rings: ring cutters, plumber Hackshaw, pliers, string method, dental cutter, etc. However, if the penis is gangrenous, necrotic, or other modalities have failed, degloving or ampu-

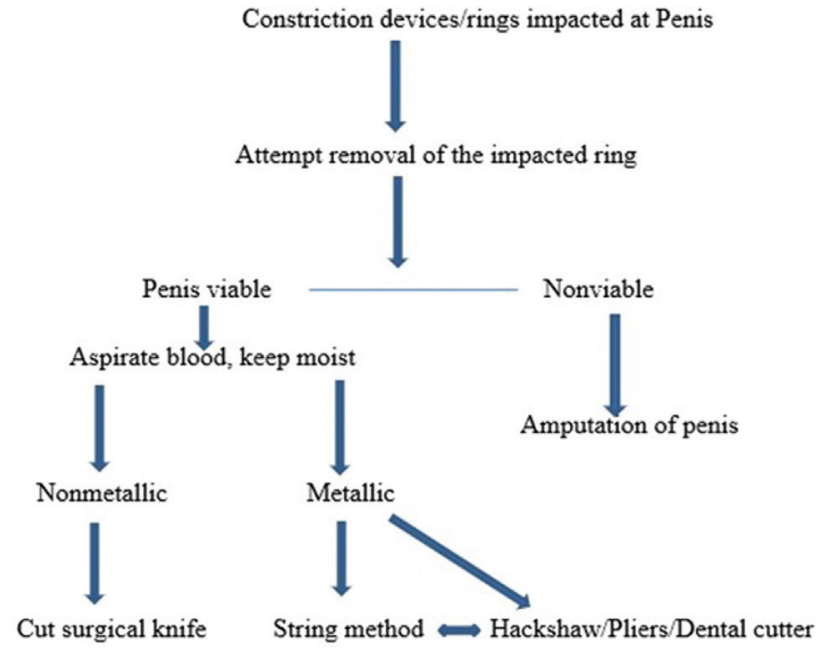

Fig. 2 Management of impacted penile ring.

tation of the penis may be indicated contingent on the extent of devitalized tissue. ${ }^{3,4}$

Our patient, a middle-aged male with no history of psychiatric illness having an erectile disorder, placed a metallic penile ring to achieve sexual stimulation. The ring got stuck, and he developed penile swelling and pain. We removed the penile ring with household pliers (-Fig. 2 ).

\section{Conclusion}

Penile constriction devices impacted in the penis is a true emergency. Removal of these constriction devices is tricky. Timely removal prevents penile complications. Follow-up of the patients and treatment of the associated disorder, erectile disorder or psychiatric disorder, is a must. The counseling of these patients to prevent further use of constriction devices is crucial and foremost.

\section{Conflict of Interest}

None declared.

\section{References}

1 Perabo FG, Steiner G, Albers P, Müller SC. Treatment of penile strangulation caused by constricting devices. Urology 2002;59 (01):137

2 Etetafia MO, Nwajei CO. Successful removal of strangulating metal penile ring using a dental handpiece. BMJ Case Rep 2014;2014: bcr2014205030. Doi: 10.1136/bcr-2014-20503

3 Ivanovski O, Stankov O, Kuzmanoski M, et al. Penile strangulation: two case reports and review of the literature. J Sex Med 2007;4 (06): $1775-1780$

4 Noh J, Kang TW, Heo T, Kwon DD, Park K, Ryu SB. Penile strangulation treated with the modified string method. Urology 2004;64(03):591 